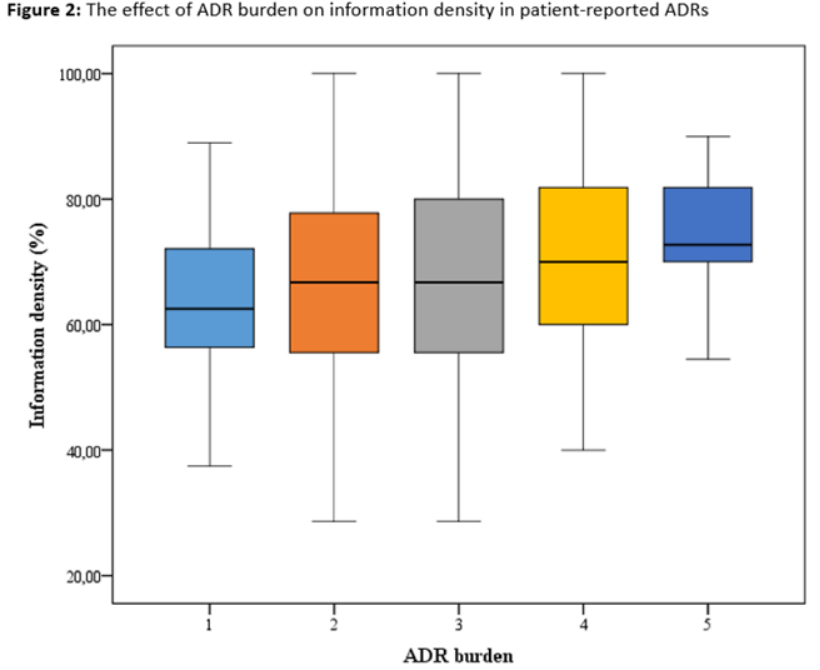

Patients reported their ADR burden on a 5-point scale, ranging from 1 (no burden) to 5 (very high burden)

Disclosure of Interests: Alexandra Laurijssen: None declared, Jette van Lint: None declared, Bart van den Bemt Grant/research support from: UCB, Pfizer and Abbvie, Consultant of: Delivered consultancy work for UCB, Novartis and Pfizer, Speakers bureau: Pfizer, AbbVie, UCB, Biogen and Sandoz., Lilian Beijer: None declared, Naomi Jessurun: None declared

DOI: 10.1136/annrheumdis-2020-eular.4124

\section{THU0638-HPR PHYSICAL ACTIVITY LEVELS OF RADIOGRAPHIC AND NON-RADIOGRAPHIC AXIAL SPONDYLOARTHRITIS PATIENTS}

T. Yuksel-Karsli ${ }^{1}$, D. Bayraktar ${ }^{2}$, D. Ozer Kaya ${ }^{2}$, Ö. Gerçik ${ }^{3}$, S. Gucenmez ${ }^{4}$, H. E. Oz ${ }^{3}$, D. Solmaz ${ }^{3}$, S. Akar ${ }^{3} .{ }^{1}$ Izmir Katip Celebi University, Faculty of Medicine, Department of Internal Medicine, Izmir, Turkey; ${ }^{2}$ Izmir Katip Celebi University, Faculty of Health Sciences, Department of Physiotherapy and Rehabilitation, Izmir, Turkey; ${ }^{3}$ Izmir Katip Celebi University, Faculty of Medicine, Department of Internal Medicine, Division of Rheumatology, Izmir, Turkey; ${ }^{4}$ Izmir Katip Celebi Unviersity, Ataturk Education and Research Hospital, Department of Rheumatology, Izmir, Turkey

Background: It is known that cardiovascular disease risk is increased in chronic inflammatory diseases. Additionally, regular exercise is one of the main components of the management of patients with axial spondyloarthritis (axSpA). However, it was reported that axSpA patients do not meet recommended physical activity levels. It is still unknown, whether the disease subgroups of axSpA play a role in participating in physical activity.

Objectives: To compare the physical activity levels among radiographic, non-radiographic axSpA patients, and healthy controls.

Methods: Thirty-three patients with radiographic axSpA (23 [70\%] male), 33 patients with non-radiographic axSpA $(23[70 \%]$ male) and 33 age and sex matched healthy controls (23 male [70\%]) were included in the study. axSpA patients were assessed regarding to disease activity (Bath Ankylosing Spondylitis Disease Activity Index; BASDAI), functional status (Bath Ankylosing Spondylitis Functional Index; BASFI), spinal mobility (Bath Ankylosing Spondylitis Metrology Index; BASMI). Physical activity level of all subjects was measured by using an accelerometer (Actigraph wGT3X-BT) which was worn on the waist for seven consecutive days.

Results: The groups were similar in terms of physical characteristics (age and body mass index) ( $p>0.05$ ). Disease related characteristics (BASMI, BASFI, BASDAI) were comparable between radiographic and non-radiographic axSpA patients $(p>0.05)$. Radiographic axSpA patients showed lesser physical activity compared to non-radiographic axSpA patients and healthy controls $(p<0.05$, Table 1$)$. There is no difference between non-radiographic axSpA patients and healthy controls regarding the physical activity levels $(p>0.05)$.
Table 1. Comparison of Groups

\begin{tabular}{|c|c|c|c|c|}
\hline & $\begin{array}{c}\text { Radiographic } \\
\text { axSpA (n: 33) } \\
\text { Median (IQR } \\
\text { 25/75) }\end{array}$ & $\begin{array}{c}\text { Non-radiographic } \\
\text { axSpA (n: 33) } \\
\text { Median (IQR 25/75) }\end{array}$ & $\begin{array}{c}\text { Healthy Controls } \\
\text { (n:33) } \\
\text { Median (IQR 25/75) }\end{array}$ & $\mathrm{p}$ \\
\hline \multicolumn{5}{|c|}{ Physical Characteristics } \\
\hline Age (years) & $41.0(32.0 / 46.0)$ & $37.0(32.0 / 40.0)$ & $33.0(28.0 / 41.0)$ & $0.093^{*}$ \\
\hline BMI $\left(\mathrm{kg} / \mathrm{m}^{2}\right)$ & $26.0(22.9 / 29.6)$ & $26.3(25.4 / 28.7)$ & $24.8(22.3 / 26.9)$ & $0.064^{*}$ \\
\hline \multicolumn{5}{|c|}{ Disease Related Characteristics } \\
\hline BASMI (score) & $2.1(1.5 / 3.9)$ & $1.5(1.1 / 2.0)$ & NA & $0.051^{\star \star}$ \\
\hline BASFI (score) & $2.4(0.7 / 3.9)$ & $1.2(0.6 / 2.9)$ & NA & $0.267^{\star \star}$ \\
\hline $\begin{array}{l}\text { BASDAI (score) } \\
\text { Physical Activity Lev }\end{array}$ & $3.6(1.6 / 5.8)$ & \multicolumn{2}{|c|}{ Physical Activity Level } & $0.519^{* *}$ \\
\hline Light Physical & 2198.0 & $2576.0^{\#}$ & 2200.0 & $0.015^{\star}$ \\
\hline $\begin{array}{l}\text { Activity } \\
\text { (min) }\end{array}$ & $(1377.0 / 2658.0)$ & $(1858.0 / 3690,0)$ & $(1846.0 / 2762.0)$ & \\
\hline Medium Physical & 188.0 & 264.0 & 363.0 & $\mathrm{p}<0.001^{*}$ \\
\hline Activity (min) & $(109.0 / 304.0)$ & $(216.0 / 446.0)$ & $(267.0 / 491.0)^{\# \#}$ & \\
\hline Vigorous Physical & 0.0 & 2.0 & 4.0 & $0.009^{\star}$ \\
\hline Activity (min) & $(0.0 / 0.1)$ & $(0.0 / 12.0)$ & $(0.0 / 19.0)^{\# \#}$ & \\
\hline Total Step Count & 42481.0 & 62872.0 & 69710.0 & $\mathrm{p}<0.001^{*}$ \\
\hline (n) & $(33651.0 / 57047.0)$ & $(53075.0 / 80160.0)^{\#}$ & $(59943.0 / 85894.0)^{\# \#}$ & \\
\hline
\end{tabular}

*Kruskal-Wallis Test, ${ }^{*}$ Mann-Whitney $\cup$ Test, ": difference between radiographic axSpA and non-radiographic axSpA, \#\#: difference between radiographic axSpA and healthy controls, IQR 25/75: Interquartile range 25/75, BMI: Body Mass Index, BASMI: Bath Ankylosing Spondylitis Metrology Index, BASFI: Bath Ankylosing Spondylitis Functional Index, BASDAI: Bath Ankylosing Spondylitis Disease Activity Index, NA: Not Applicable, $p<0.05$

Conclusion: The results of the present study suggest that radiographic damage in axSpA may alter the physical activity levels. Every effort should be taken to increase physical activity levels in axSpA patients, especially in radiographic cases.

Acknowledgments: This project was supported by Izmir Katip Celebi University Scientific Research Projects Coordinatorship.

Disclosure of Interests: None declared

DOI: 10.1136/annrheumdis-2020-eular.4231

\section{THU0639-HPR GOUT DISEASE ACTIVITY SCORE - FURTHER EVALUATION OF CONSTRUCT AND CONVERGENT VALIDITY}

M. Zlatkovic-Svenda ${ }^{1,2}$, M. Radak-Perovic ${ }^{1} .{ }^{1}$ Institute of Rheumatology, University of Belgrade School of medicine, Belgrade, Serbia; ${ }^{2}$ Medical Faculty, University of East Sarajevo, Republika Srpska, Foca, Bosnia and Herzegovina

Background: A new instrument for measuring of disease activity in gout is a 4-variable gout disease activity score (GAS), announced in 2016 (1). GAS calculates self-reported number of attacks in the last year, patient visual analogue scale (VAS) for gout severity, serum uric acid level $(\mathrm{mg} / \mathrm{dL})$ and the number of tophi, and has shown good psychometric properties (1).

Objectives: to test GAS in patients with gout and to evaluate its construct and convergent validity

Methods: 74 patients with gout were evaluated successively, as they entered the Institute of Rheumatology in Belgrade. Construct validity was assessed by associationos between GAS and SF-36, using Spearman's rank correlation coefficients. Convergent validity was evaluated by testing the ability of the GAS score to distinguish between patients grouped by perceived disease severity, perceived general health and physicians perceived disease severity by using Kruskal-Wallis one-way analysis of variance. Computer statistic program SPSS 20.0 was used for data evaluation.

Results: For the construct validity, significant correlations were found between GAS and SF-36 subscales, specially for Body pain ( $r=-0.725)$, Physical functioning ( $r=-0.684)$ and Physical limitations $(r=-0.563)$, whereas Social functioning, Mental health, and Vitality were less affected. Correlation between GAS and Physical component scale of the SF-36 was the most prominent $(r=-0.780)$. For the convergent validity, significant differences in GAS scores were found between patients grouped by perceived general health $(p<0,01)$ and perceived disease severity $(p<0,01)$, and by doctors perceived disease severity $(p<0,01)$, demonstrating the ability of the GAS to distinguish between subgroups of patients.

Conclusion: GAS has shown good psyshometric properties in Serbian cohort of patients and has proved to be valid and reliable tool for use in clinical practice. 